\title{
ENHANCING READING COMPETENCE THROUGH THE BRAILLE SYSTEM FOR VISUALLY IMPAIRED PEOPLE: A PRELIMINARY STUDY
}

\author{
Edgar Guadia Encalada*, Cristina del Rocío Jordán, \\ Verónica Elizabeth Chicaiza and Sarah Jacqueline Pazmiño \\ Universidad Técnica de Ambato, Ecuador
}

\begin{abstract}
This paper addresses the issue of the development of the English language reading skills and subskills using the Braille System as the fundamental tool for visually impaired people. The purpose of this study was to determine the relationship between the use of the Braille System and the reading skill competence. This research was applied to 21 pupils with different blindness conditions and from 10 to 32 years old who belong to the Special Education School "Julius Dophner" in the city of Ambato, Ecuador. This preliminary study was carried out using a quasi-experimental design, where pre-tests and post-tests were applied during a three-week period. Pupils took active part in the reading of the different primers at the beginning and after the treatment process. A $t$-test was used to examine the hypothesis. The results revealed that the improvement in the English language reading for specific information subskill through the Braille system was meaningful. Additional testing should be done to validate the scores obtained by visually impaired students with the use of this tool. Pupils showed a positive and very enthusiastic attitude about the learning process of the English language through this tool with which they are familiar.
\end{abstract}

Keywords: Braille system, reading competence, visually impaired people, primers

In the educational field, the inclusion of people with disabilities is especially important to make the social integration of any country a reality, where the higher education level plays a significant role in achieving it. The mere fact that students with visual impairment can know a second language would not only enhance their knowledge of another culture and have accessibility to obtain better jobs but also increase their ego by verifying that their deficiency is no obstacle for achieving success.

Hamid et al. (2019) claimed, "Braille reading, however, is a complex skill and prolonged visual deprivation is thought to greatly enhance its acquisition" (p. 16). However, their reading or writing skills may not meet the same expectations, perhaps due to lack of time, teaching materials, methodologies, strategies, lack of experience or motivation of both students and teachers.

The short amount of time spent in developing reading skills is a disadvantage. The little use of tactile Braille teaching material causes demotivation for students in the learning process. Gori et al. (2016) concluded, "individuals with visual impairments might present a delayed or impaired development of spatial capabilities" (p. 80). In fact, it should be understood that not every student fits the same strategies; there are appropriate reading strategies for blind students that must be implemented by taking into account first, that each student has their learning style and their own study needs. 
These could be the first steps to promote in these students the study of foreign languages with a futuristic purpose that consists of an integration in professional fields that require mastery of languages such as interpreters, translators, language teachers, among others.

\section{Braille system and reading skills}

In the research work with the theme called "English Language Learners: Experiences of Teachers of Students with Visual Impairments Who Work with This Population" (Topor \& Rosenblum, 2013), the author sets out as the main objective: To search for information on training needs from teachers, their knowledge of instructional strategies and methods and about their preparation to work with blind children who are learning English, which come from different cultures and languages.

This research has a quantitative approach, the methodology is quantitative, since one online survey was applied to professors from the United States and Canada who impart their knowledge to blind students. The information was approved, tabulated and processed at the University of Arizona. These data allowed Topor and Rosenblum to verify the hypothesis with the following conclusions:

- The 66 participants have various levels of knowledge about English language teaching strategies. Some of them use common instructional strategies for language teaching according to the needs that the student requires. When the teacher imparts Braille to his students, he almost always does it in English.

- Few students who read in Braille were provided with material or instructed in their first language. Participants said that Braille reading instruction in beginning students occurred in English.

The Braille System as the main pedagogical tool for the reading development process, plus the application of teaching strategies to students with visual disabilities, are the main factors of this research. Students will be aware of techniques and strategies to improve reading skills using the Braille alphabet.

On the other hand, teachers could have training on strategies applicable to their students and thus be aware of current and active techniques in the teaching-learning process, with the sole purpose of providing competent education.

In the following investigative magazine (García \& Pereira, 2006) with the theme "Understanding texts and modalities of access to information: comparison of yields between blind and sighted people", the authors set out as the main objective: To carry out a study of comparative analysis on the performance of blind and sighted people in understanding texts, depending on their academic level, and the different access modalities (Braille, ink, voice synthesis and human voice recording), and determine the development pattern of the processes of understanding texts of blind people.

This research has a qualitative approach, since test 5 (evaluation of reading comprehension) was applied, to both blind and sighted people. A total of 259 subjects participated in the research, which were distributed in two samples, one of blind people (122) and another one of sighted people (137), 
which were divided into five subgroups according to their educational level. The information was evaluated according to the answers of each text. On this application, the researchers obtained the following conclusions:

- Braille readers have a lower reading speed than ink readers. Reading speed continues to improve among people with university education.

- Once the sensory decoding processes are automated, there is a notable increase in performance in understanding, which consumes a large part of the subjects' cognitive resources, which, together with the Braille system's own limitations, would cause lack of progress in reading speed.

- The total reading comprehension indices are practically identical between blind and sighted people when they use Braille and ink texts, respectively, which would conform that the perceptual properties of touch limit the reading speed, but not the ability to understand.

The authors' criteria of this research is that reading comprehension is more important than reading speed; since for them, performance is what really counts. The perspective of this project was to reach a reading comprehension in the English language by using Braille teaching materials for blind students.

\section{Reading Subskills}

Within the development of the English language reading skills are reading sub-skills, and a reading process to achieve understanding.

When we read, it is not necessary to read everything in the text, the reasons for reading, influences how to read, that is why it is necessary to use the sub-skills or abilities according to Spratt (2011).

- Reading for gist (skimming)

This sub-skill is used when the teacher wants the student to obtain a global or general understanding of the entire text.

- Reading for specific information (scanning).

In this sub-skill the text is manipulated with greater precision since it seeks to obtain specific information such as telephone numbers, names, addresses, etc. When this skill is applied, you don't need to read all the text.

- Reading for details

With the use of this sub-skill, a student, for example, could differentiate whether the sentences in a text are written in the present simple or continuous. 
- Inferring

This sub-skill is used when one wishes to deduce moods, opinions, emotions or attitudes of the writer, inferring only by the way of expressing himself in the text; this involves the words used in the text, style (formal / informal), lexicon, etc.

- Deducing meaning from context

This sub-skill helps students deduce the meaning of unknown words without using a dictionary but rather through context.

\section{- Predicting}

This sub-skill consists of searching for clues and obtaining a reading forecast before starting to read it using the topics or sub topics of a reading, the name of the author, and linking them with the general knowledge that the student has.

- Understanding text structure

This ability helps the student to decipher the development of a text. For example, if the student is going to read a letter from a friend who lives abroad, the student must assume that he will first read the greeting, then information about his friend, then a possible invitation to somewhere, and finally a cordial farewell.

- Intensive Reading

This sub-skill is used when the intention of reading is purely academic with an educational purpose of language teaching.

- Extensive Reading

This sub-skill is used when reading for one's own will (by pleasure), for example when reading selfinterest books, magazines, articles, etc.

- Silent Reading

The objective of this sub-skill is to achieve a clear understanding of the text.

- Out-loud reading

The objective of this sub-skill is to check the pronunciation and intonation of the student.

To achieve great reach in reading skills, the student must continue the next process following to: 
- Pre-reading

At this stage the teacher intends that students predict the information they are going to read by asking them questions about the topic, vocabulary, activities to boost intuition through past experiences, etc.

- Reading

Students develop the reading activity by establishing the purpose or objective of reading. For this, the teacher must establish what sub-skill they will apply.

- Post-reading

Students perform post-reading activities. The teacher could also organize presentations, small debates and discussions on the subject area, where oral skills would lead the process.

The use of sub-skills is consistent with the purpose of reading, and all of these can be used by blind people. In the same way, the reading process since it involves the understanding of words, sentences and making sense of the text through their experiences and knowledge.

This study is focused on the reading for specific information sub skill (scanning) using the Braille system as the main pedagogical tool.

\section{Visual disability}

The term "visual disability" covers a broad range of medical conditions. In developing accessible apps and programs, students are generally separated into two categories for usability purposes: low vision and functionally blind. Low vision constitutes a majority of the visually impaired, including low visual acuity, loss of visual field or low peripheral vision, photophobia (inability to look at light), diplopia (double vision), visual distortion, perception difficulties, or color blindness. McQuiggan et al. (2015) stated:

Students with severe visual impairments have different needs. The difference between those with low vision and severe visual impairments often lies in how they are able to consume content. While persons with low vision will be able to make adjustments to devices to read (by enhancing contrast or text size, for instance), persons with severe visual impairment will use braille or audio to adapt (p. 281).

Taking into account the aforementioned, it is important to know the skills of this population. Susanto and Nanda (2018) concluded that "visually impaired students actually can have unique ways of learning foreign language supported by the assistive technology" (p. 83).

Since the absence of vision does not affect cognitive processes, learning can always be generated in these students, which is why it is necessary to have various materials and strategies that allow students to compensate for this absence of vision with their remaining senses, thus generating meaningful learning that responds to their abilities and needs. 
Some individuals with the best possible correction can see or distinguish, although with great difficulty, some objects at a very short distance. In the best of conditions, some of them can read the printed letter when it is of sufficient size and clarity, but generally more slowly, with considerable effort and using special aids. Depending on their remaining visual acuity, individuals may require particular types of optical aids.

Eligi and Mwantimwa (2017) stated, "Students with disabilities may, in fact, face relevant difficulties in terms of both 'accessing and in using' electronic learning tools and, depending on the type of impairment, the obstacles encountered may vary considerably" (p. 88).

These should be taken into account for the preparation of material, which will allow them to participate in the learning process because they will have the possibility of being active subjects in the academic process according to their capacities and abilities, achieving an active and effective inclusion in the different academic spaces.

Thus, to consider that a person is visually impaired, it must be taken into account that the person's ability to cope with daily tasks and the amount of support that is required are evaluated, there is talk of legal blindness This concept of legal blindness includes the situation of people who present a visual functional impairment that prevents them from having a visual acuity greater than the limit of $1 / 10$ or a visual field greater than 10 degrees.

It is considered legal blindness when the person has visual residue, but it is not enough to allow them to carry out daily tasks such as driving, or moving in a safe way, making their interaction with the environment autonomously difficult.

On the other hand, for ophthalmologists, blindness is "when someone is totally deprived of vision, not capable of having a visual sensation, nor with high intensity light sources" (Checa Benito et al., 2000, p. 36).

When a student arrives in the classroom with blindness or visual impairment, what is sought is to make most of his abilities and skills. Salem (2017) concluded, "Hence, students need teacher assistance, rather say instructional scaffolds, to understand and to comprehend the message lying behind the reading tasks" (p. 97).

In fact, the role of the teacher into the class is crucial for visual impairment students that is why special materials must be developed to train the person in such a way that they can manage in different contexts independently.

The National Organization of the Blind Spanish (Organización Nacional de Ciegos Españoles [ONCE], 2011) defined the assessment criteria to understand the visual capacity of each individual as follows (pp. 79-81):

- Normal vision: when the visual acuity of the best eye is greater than or equal to 0.8 , and the visual field is normal; 
- Almost normal vision: if the visual acuity of the best eye is between 0.7 and 0.5 , the visual field being normal;

- Subnormal vision: visual acuity is between 0.4 and 0.3 or the visual field is limited to $40^{\circ}$

- Low vision: visual acuity between 0.25 and 0.12 or the visual field decreased to $20^{\circ}$.

- Legal blindness: if the visual acuity is equal to or less than 0.1 or the visual field is reduced to $10^{\circ}$ or less. This situation allows a person to be considered "legal" as blind and be, for example, affiliated with ONCE. At this point, it should be clarified that the simple reduction of the visual field to $10^{\circ}$, even though a visual acuity of 1.0 was preserved, allows the consideration of legal blindness.

Taking into account the categories described above, to start the diagnosis of a person with blindness, it must be borne in mind that blindness is not a single condition, but that it also carries a series of characteristics that allow defining the person's condition.

Thus, visual impairment is classified as follows:

Moderate visual impairment: Visual acuity less than $6 / 18$, but equal to or greater than $6 / 60$ (between 20/70 and 20/160). The person can discriminate fine details of objects 6 meters away, when a person without visual difficulties could do it 18 meters away.

Serious visual impairment: Visual acuity less than 6/60, but equal to or greater than $3 / 60$ (between $20 / 200$ and 20/400). The person is able to distinguish shapes and colors with little precision, he manages to observe them a meter away, although he cannot distinguish details, he requires supports to function in daily life.

Blindness or amaurosis: Visual acuity less than 3/60 (equivalent to 20/1250) (there may or may not be light perception). The person does not perceive any visual stimulation.

It should also be taken into account if visual loss occurs from an early age or in adulthood, therefore early detection is important, in order to determine if these are congenital, acquired and the resulting condition after diagnosis, if it is possible to carry out since childhood, early intervention can be established according to the diagnosis.

\section{Method}

To measure the relationship between the use of Braille system and the English language reading for specific information subskill where the text is manipulated with greater precision since it seeks to obtain specific information such as telephone numbers, names, addresses, etc., and learners don't need to read all the text; a group of 21 visually impaired students was selected through a quasi-experimental design according to the following details: 
Table 1

Subjects' age

\begin{tabular}{lll}
\hline Age & Frequency & Percentage \\
\hline 10 & 2 & 9.5 \\
11 & 2 & 9.5 \\
13 & 4 & 19.0 \\
15 & 3 & 14.3 \\
16 & 2 & 9.5 \\
17 & 1 & 4.8 \\
19 & 1 & 4.8 \\
21 & 2 & 9.5 \\
23 & 1 & 4.8 \\
28 & 1 & 4.8 \\
30 & 1 & 4.8 \\
32 & 1 & 4.8 \\
\hline Total & 21 & 100 \\
\hline
\end{tabular}

Table 1 shows the age of the study subjects where 4 subjects are 13 years old who represent a 19 percent of the sample.

Table 2

Gender

\begin{tabular}{lll} 
Gender & Frequency & Percentage \\
\hline Male & 9 & 42.9 \\
Female & 12 & 57.1 \\
Total & 21 & 100 \\
\hline
\end{tabular}

In Table 2, it is important to highlight that from the total sample, 9 subjects were male and 12 females.

Table 3

Type of blindness

\begin{tabular}{lll}
\hline Description & Frequency & Percentage \\
\hline legally blind & 8 & 38.1 \\
seriously visually impaired & 6 & 28.6 \\
low vision & 7 & 33.3 \\
\hline Total & 21 & 100 \\
\hline
\end{tabular}

Source: Special Education School “Julius Dophner”.2020

Table 3 shows that 8 subjects are legally blind, 6 are seriously visually impaired and 7 subjects with low vision condition, from them. 
For the initial experiment, 5 primers were prepared with 10 English words each written using the Braille system. The words were chosen by taking into account their similarity in the written part to those words in the Spanish language.

The level of difficulty was ascending. Primer 1 contained 3 letter words, Primer 2 with 4 letter words, Primer 3 contained 5 letter words, and the fourth primer contained 6 letter words, and finally, the fifth primer with 7 letter words as shown in Figure 1.
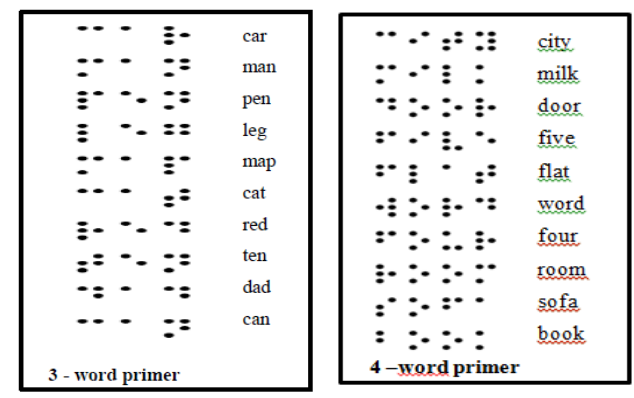

\begin{tabular}{|c|c|c|c|}
\hline 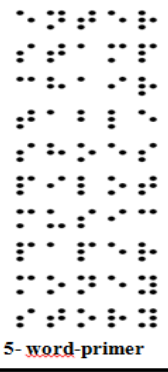 & $\begin{array}{l}\text { enter } \\
\text { stamp } \\
\text { chair } \\
\text { table } \\
\text { shoes } \\
\text { pilot } \\
\text { music } \\
\text { paper } \\
\text { money } \\
\text { story }\end{array}$ & 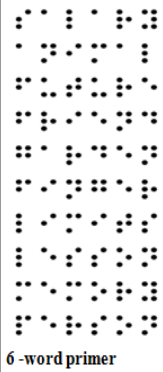 & $\begin{array}{l}\text { salary } \\
\text { animal } \\
\text { future } \\
\text { friend } \\
\text { garden } \\
\text { finger } \\
\text { limits } \\
\text { lesson } \\
\text { memory } \\
\text { person }\end{array}$ \\
\hline
\end{tabular}

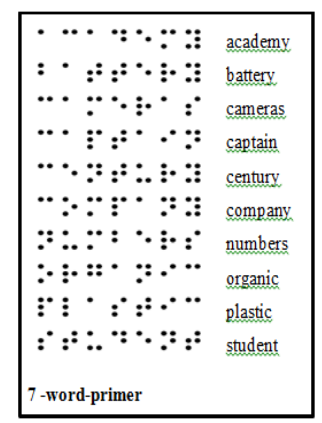

Figure 1. Primer stimuli

The primers were given to participants one by one so they could go through them and say what they read. As reading was the primary goal, little or no attention to pronunciation was paid. For data collection, a register table was used both in the application of the pre-test and in the post-test, the number of words that effectively read were registered as the study subjects read the primers. After a week of explanation in pronunciation of the different words and sounds by permanent repetition, the primers were applied for a second time and the results were registered as shown in Table 4. 
Table 4

Control Table

\begin{tabular}{llll}
\hline $\begin{array}{l}\text { Subject } \\
\text { Number }\end{array}$ & $\begin{array}{l}\text { Prestest } \\
\text { (Words Read Effectively) }\end{array}$ & $\begin{array}{l}\text { Postest (Words Read } \\
\text { Effectively) }\end{array}$ & Sig. Difference \\
\hline 1 & 25 & 35 & 10 \\
2 & 35 & 43 & 8 \\
3 & 37 & 46 & 9 \\
4 & 28 & 38 & 10 \\
5 & 33 & 42 & 9 \\
6 & 39 & 48 & 9 \\
7 & 41 & 48 & 7 \\
8 & 22 & 37 & 15 \\
9 & 38 & 44 & 6 \\
10 & 43 & 49 & 6 \\
11 & 45 & 50 & 5 \\
12 & 21 & 36 & 15 \\
13 & 24 & 39 & 15 \\
14 & 18 & 31 & 13 \\
15 & 26 & 39 & 13 \\
16 & 32 & 43 & 11 \\
17 & 37 & 47 & 10 \\
18 & 42 & 50 & 8 \\
19 & 43 & 48 & 5 \\
20 & 41 & 47 & 6 \\
21 & 20 & 31 & 11 \\
& & $\square$ & 9.6 \\
\hline
\end{tabular}

The control table shows the differences in the number of words which were read in the pretest and posttest. The significance difference media is $\bar{x}=9.6$.

\section{Results}

Table 2 and 3 show the results obtained from the study group, which indicate that when comparing the related sample statistics for pretest and post-test, it is evident that the difference is significant, since the pretest had a mean of 32.86 while the posttests had a mean of 42.43 . When performing a $t$-test to analyze the results, a $p$-value $<0.001$ was obtained.

The following hypothesis was stated for this study:

$$
\begin{aligned}
& \mathrm{H} 0=\overline{\mathrm{x}} 1=\overline{\mathrm{x}} 2 \\
& \mathrm{H} 1=\overline{\mathrm{x}} 1 \neq \overline{\mathrm{x}} 2
\end{aligned}
$$


Then, with 20 degrees of freedom, with a significance level of 0.05 and with the $t$-value of -13.564 and the critical value of 2.086 or -2.086 , the value of $t$ is outside the acceptance zone, then, H0 is rejected and $\mathrm{H} 1$ is accepted, that is, there is a meaningful difference between the mean of the pretest and the posttest, as shown in Figure 2.

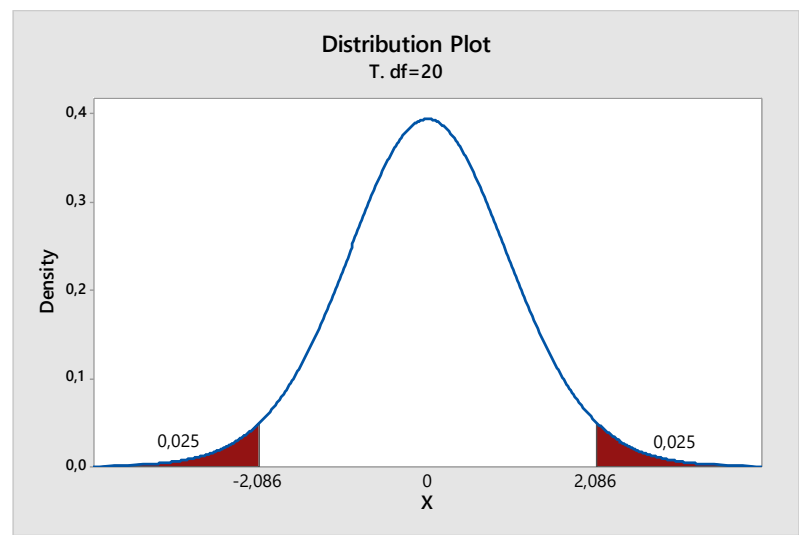

Figure 2. Distribution plot

\section{Limitations}

The Braille system has exciting potential as an English reading tool for visually impaired people; however, some limitations of this study are worth mentioning. First, the different types of visual disability since 9 students have legal blindness between 20/200, 8 of them have total blindness, and 4 students have severe low vision. Second, the level of reading development using the Braille system in their first language was limited in some of them. Nevertheless, after the explanation and practice of the different words, they were able to read them more effectively.

Another key factor by which students' performance was deficient at the beginning could be that they were not familiar with the English language since in that institution there is no teacher for teaching this language because of budget restrictions.

\section{Discussion}

Nowadays, inclusive education is something that cannot be neglected; it is mentioned in The Ecuadorian Constitution in the Fifth Section, art. 46 numeral 3: "Preferential attention for the full social integration of those who have disabilities. The state will guarantee their incorporation into the regular education system and into society." (National Assembly, 2008). It is also known for human rights and as professionals with social responsibility, this vital issue for inclusion cannot be ignored, considering that English has become a world language used for all types of communication.

The current trend is to enroll special education students in integration centers, since this school system is considered to offer a better academic level as well as greater possibilities for social interaction. Specific centers are generally recommended for children whose complex needs cannot be met in ordinary centers. 
The visually impaired student in school integration has to adjust to a visual material rarely adapted to be enjoyed tactilely. Foreign language books have a very pictorial design and therefore, the teaching of this subject is particularly complex when there is a blind child in the classroom. Furthermore, language teachers are not academically prepared to make specific curricular adaptations for this type of disability, so coupling these students to the class generally involves excessive additional work.

As far as the reading process is concerned, most of the students use both hands to read the cards, of each hand they only use the index finger, although if differences in skill are noticed, being the smallest subjects the least skilled and finding more variability in the use of one or two hands. The general reading movement does not seem to vary exclusively by age level and type of visual impairment.

The students showed a favorable attitude towards learning English through the Braille system since it is a tool with which they are mostly familiar, so it is recommended that further research be done on different strategies and the elaboration of specific didactic resources for promoting the reading learning process with this group of students who really deserve an opportunity for personal and professional growth.

Then, curricular adaptations are needed which refer to the attempt to adapt teaching to the peculiarities and needs of each student. It also refers to the recognition of the classroom as a heterogeneous and diverse group of students, for which there is no single educational response.

Thus, curricular adaptations are strategies for adapting the general curriculum to the individual needs of students. The starting point for the adaptations is located in a single general curriculum common to all students for compulsory education.

\section{Conclusions}

Once the research was completed, the utility of the Braille system as a pedagogical tool for the reading process in visually impaired students has been defined, through the statistical analyses obtained. In addition, it was evident that students are familiar with the different stages of reading and there is an acceptance by them, but they are unaware of many reading sub-skills such as reading for gist, reading for details, inferring, predicting and so on that they could put into practice for better academic performance through further practice which requires more intensive training.

What's more, the limited application of strategies and methods appropriate for visually impaired students results in a low level of academic performance. Not every student can be evaluated in the same way and not every student fit with the same strategies and methods as a sighted student.

There are numerous strategies that teachers could use when evaluating a visually impaired student, first considering the student needs when learning a second language; these could be personal, learning, and professional.

Finally, it can be affirmed that the absence of didactic material in ink and Braille for the development of the reading skill of the English language causes innumerable negative effects for visually impaired 
students such as demotivation and lack of interest when feeling relegated from a true teaching-learning process.

An alternative to change this reality would be to promote trainings on inclusive methodological strategies aimed at English teachers to improve the process of teaching English language reading skills using the Braille system for students with visual disabilities.

Further studies will be required to fulfill all the academic needs of visually impaired students according to their level of blind conditions and their age.

\section{References}

Checa Benito, F. J., Robles, M. M., Martín Andrade, P., Núñez Blanco, M. A., \& Vallés Arándiga, A. (2000). Aspectos evolutivos y educativos de la deficiencia visual [Evolutionary and educational aspects of visual impairment] (Vol. I). Organización Nacional de Ciegos Españoles [ONCE; National Organization of the Blind Spanish]

Eligi, I., \& Mwantimwa, K. (2017). ICT accessibility and usability to support learning of visuallyimpaired students in Tanzania. International Journal of Education and Development Using Information and Communication Technology, 13(2), 87-102.

García, L. G, \& Pereira, M. P. (2006). Comprensión de textos y modalidades de acceso a la información: comparación de rendimientos entre personas ciegas y videntes [Comprehension of texts and methods of access to information: Comparison of performances between blind and sighted people]. Integración, Revista Sobre Ceguera y Deficiencia Visual, 48, 7-24.

Gori, M., Cappagli, G., Tonelli, A., Baud-Bovy, G., \& Finocchietti, S. (2016). Devices for visually impaired people: High technological devices with low user acceptance and no adaptability for children. Neuroscience \& Biobehavioral Reviews, 69, 79-88. https://doi.org/10.1016/j.neubiorev.2016.06.043

Hamid, A., Mohsin, M. S., \& Khalid, M. N. (2019). Effectiveness of Urdu reading Braille characters with the help of tactile and visual clues. Journal of Research in Psychology, 1(1), 16-20. https://doi.org/10.31580/jrp.v1i1.853

McQuiggan, S., McQuiggan, J., Sabourin, J., \& Kosturko, L. (2015). Mobile learning: A handbook for developers, educators, and learners. John Wiley \& Sons.

National Assembly. (2008). Constitution of the Republic of Ecuador.

Organización Nacional de Ciegos Españoles. (2011). Discapacidad visual y autonomía personal: Enfoque práctico de la rehabilitación [Visual impairment and personal autonomy: A practical approach to rehabilitation].

Salem, A. A. M. S. (2017). Scaffolding reading comprehension skills. English Language Teaching, 10(1), 97-111. https://doi.org/10.5539/elt.v10n1p97

Spratt, M. W. (2011). The TKT (Teaching Knowledge Test) Course. Cambridge University Press.

Susanto, S., \& Nanda, D. S. (2018). Teaching and learning English for visually impaired students: An ethnographic case study. English Review: Journal of English Education, 7(1), 83-92. https://doi.org/10.25134/erjee.v7i1.1530

Topor, I., \& Rosenblum, L. P. (2013). English language learners: Experiences of teachers of students with visual impairments who work with this population. Journal of Visual Impairment \& Blindness, 107(2), 79-91. 